University of Windsor

Scholarship at UWindsor

$6-27-2018$

\title{
Chinese Enclave Protections Among Married Chinese American Women: Exploratory Secondary Analysis of Colon Cancer Survival
}

\author{
Luisa Kcomt \\ University of Windsor \\ Kevin Gorey \\ University of Windsor
}

Follow this and additional works at: https://scholar.uwindsor.ca/socialworkpub

Part of the Family, Life Course, and Society Commons, Medicine and Health Commons, Race and Ethnicity Commons, and the Social Work Commons

\section{Recommended Citation}

Kcomt, Luisa and Gorey, Kevin. (2018). Chinese Enclave Protections Among Married Chinese American Women: Exploratory Secondary Analysis of Colon Cancer Survival. Ethnicity \& Health, 1-14.

https://scholar.uwindsor.ca/socialworkpub/61

This Article is brought to you for free and open access by the School of Social Work at Scholarship at UWindsor. It has been accepted for inclusion in Social Work Publications by an authorized administrator of Scholarship at UWindsor. For more information, please contact scholarship@uwindsor.ca. 


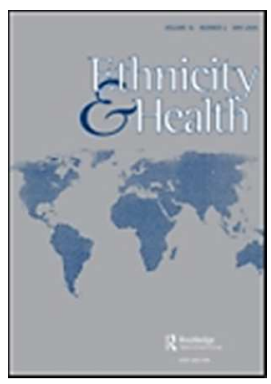

\section{Chinese Enclave Protections among Married Chinese} American Women: Exploratory Secondary Analysis of Colon Cancer Survival

\begin{tabular}{|r|l|}
\hline Journal: & Ethnicity and Health \\
\hline Manuscript ID & CETH-2017-0238.R2 \\
\hline Manuscript Type: & Original Manuscript \\
\hline Keywords: & $\begin{array}{l}\text { Chinese American, ethnic enclave, gender, marriage, poverty, colon cancer } \\
\text { survival }\end{array}$ \\
\hline
\end{tabular}

\section{SCHOLARONE}

Manuscripts 


\title{
Chinese Enclave Protections among Married Chinese American Women: Exploratory Secondary Analysis of Colon Cancer Survival
}

\author{
Luisa Kcomt $^{\mathrm{a}}$ and Kevin M. Gorey \\ ${ }^{\text {a }}$ School of Social Work, University of Windsor; kcomtl@uwindsor.ca \\ ${ }^{\mathrm{b}}$ Corresponding author. School of Social Work, University of Windsor, 167 Ferry Street, \\ Windsor, Ontario, N9A 0C5, Canada; gorey@uwindsor.ca \\ Telephone: 519 253-3000, ext. 3085
}


Protective Effects of Ethnic Enclaves and Marriage

\begin{abstract}
Objective: Like the barrio advantage theory related to Mexican Americans, a theory about the protective effects of Chinese American enclaves is developing. Such protections were examined among socioeconomically vulnerable people with colon cancer.
\end{abstract}

Design: A colon cancer cohort established in California between 1995 and 2000, and followed until the enactment of the Affordable Care Act was utilized in this study. Secondary analysis was conducted on the 5-year survival among 127 Chinese Americans and 4,524 other Americans (3,810 non-Hispanic white and 714 Hispanic people). A third of the original cohort was selected from high poverty neighborhoods. Chinese American enclaves were neighborhoods where typically $25 \%$ or more of the residents were Chinese Americans. Effects were tested with Cox regressions and group differences described with age and stage-standardized survival rate ratios (RR).

Results: Though they were less adequately insured, Chinese American women residing in Chinese American enclaves (63\%) were more likely to survive than were other Americans $(50 \%$, $\mathrm{RR}=1.26$ ). The protective effect of being married was also larger for Chinese Americans $(R R=1.31)$ than for others $(R R=1.17)$. Chinese American women $(61 \%)$ were more likely than men (46\%) to live in such enclaves and a large enclave survival advantage was observed among Chinese American women only $(\mathrm{RR}=1.59)$.

Conclusions: There is consistent evidence of the relatively protected status of Chinese American women, particularly those who were married and resided in Chinese American enclaves. Mechanisms that explain their apparent advantages are not yet well understood, though relatively large, kin-based social networks seem instrumental. Research on the influence of social networks as well as the possible effects of acculturation is needed. This study also exposed structural 
1

2

3

4

5

6

7

8

9

10

11

\section{Protective Effects of Ethnic Enclaves and Marriage}

inequities related to the institutions of marriage, health care and communities that disadvantage others. Policy makers ought to be aware of them as future reforms of American health care are considered.

Keywords: Asian American; Chinese American; colon cancer; ethnic enclave; ethnicity; gender; health care reform; health insurance; marriage; poverty; race; survival 
Protective Effects of Ethnic Enclaves and Marriage

\section{Introduction}

One out of every 20 United States citizens is now an Asian American. One-third of them have immigrated to California where their aggregate immigration rate is now twice that of Latin Americans (Pew Research Center 2017; Public Policy Institute of California 2017; U.S. Census Bureau 2017). Not surprisingly, many choose to live in ethnic enclave neighborhoods with relatively high spatial concentrations of Asian Americans (Gomez et al. 2010). Because the Chinese are the most prevalent Asian American population, the most prevalent type of Asian enclave in California is the Chinese American enclave. Broadly synonymous to cultural community, the term ethnic enclave refers to racially segregated neighborhoods often located in urban settings which are defined by ethnic culture (Chang 2010). Chinatown and Koreatown are examples of Asian American enclaves (Chang 2010; Zhou and Cho 2010; Zhou and Logan 1989). They may serve as a place of residence and/or as a place of work. Ethnic enclaves offer tangible and intangible benefits including the opportunity to build social relations which may have been disrupted by migration, rebuild ethnic institutions, and provide a structure for economic opportunities which enables the potential for social mobility (Zhou and Cho 2010). Evidence is developing to suggest that they are "structurally and socially resourceful places to live" because such neighborhoods pool social capital and may concentrate cultural strengths and resiliencies (Walton 2015, 508).

Similar to the "barrio advantage" theory related to Hispanic Americans generally, and Mexican Americans specifically, a theory about the protective effects of Asian/Chinese American enclaves is developing. In fact, Chinese American enclaves have been associated with healthy behaviors like the consumption of lower fat and less processed foods as well as better self-reported health statuses (Osypuk et al. 2009; Walton 2015). However, such evidence has not 
been unequivocal. Unlike the longstanding evidence which supports the theory that Mexican American barrios are relatively healthy places to live and offers protections against morbidity and mortality, such evidence regarding Chinese American enclaves do not exist yet (Eschbach et al. 2004; Markides and Coreil 1986; Ruiz, Steffen and Smith 2013). To date, there has been a paucity of research which explores the characteristics of the Chinese American population or the moderating effects of Chinese American enclaves. The current study will address this gap in the literature.

Colon cancer is among the top three most common and deadliest cancers among Chinese Americans and non-Hispanic white people alike. Among Chinese Americans in certain contexts, the diagnosis may occur later in the course of the illness which impacts their survival (Edwards et al. 2014; Linn et al. 2002; Luo et al. 2004). In other contexts, Chinese Americans have been observed to have a better survival rate than non-Hispanic white, Hispanic, African American, or other Asian Americans from colon and other cancers (Lin et al. 2015; Sun et al. 2007). Like the pattern of paradoxical findings observed among low-income or inadequately insured Hispanic people who reside in Hispanic enclaves (Escobar, Sivaram and Gorey 2018; McWilliams et al. 2004; Turra and Goldman 2007), Chinese Americans of low socioeconomic status (SES) seem to exhibit a particular advantage on cancer survival compared to other ethnic groups with similarly low SES (Xu et al. 2017). Therefore, it can serve as a useful sentinel to explore possible protective factors in Chinese American enclaves. Indeed, Chinese Americans are not a homogeneous population, as individuals may differ in their class, potential for social mobility, and level of acculturation to the dominant society (Chang 2010). Yet, these descriptive findings on the influence of demographic and socioeconomic characteristics suggest complex interactions that may be associated with being Chinese American. 
Research in the same context as the present study has shown that gender and marital status interact with health insurance adequacy which influences cancer survival. For example, among women with colon cancer, poverty and inadequate health insurance coverage were more prevalent among unmarried women (Levitz et al. 2015). Among those living near or below the poverty line with colon cancer, private health insurance was associated with survival among married women, but not men. In addition, unmarried women lived in lower income neighborhoods more than unmarried men (Campbell et al. 2016). These studies reveal that marriage serves as a protective factor, especially among the most socioeconomically vulnerable. In general, unmarried people have fewer assets and less discretionary income to cover the direct and indirect costs of health care. Moreover, "structural inequities related to the institutions of marriage and health care seem to affect women and men quite differently" (Campbell et al. 2016, 260).

Chinese Americans, particularly women, tend to be married for longer periods of time than other Americans, including other Asian Americans (Chen et al. 2015; Hashiguchi 2012). As with other American women, marriage is positively associated with adequate health insurance coverage among Chinese American women (Levitz et al. 2015; Tan 2009). Marriage and/or health insurance have also been significantly associated with a range of behaviors among Chinese Americans that, together, could bode for better colon cancer outcomes. Among them are psychological well-being, health literacy, and participation in cancer screening, including colon cancer screening (Chow 2010; Simon, Li and Dong 2014; Todd, Harvey and HoffmanGoetz 2011). Moreover, kin-centered social networks among Chinese Americans tend to be larger and more instrumental than those of other Asian Americans (Wen, Fang and Ma 2014). In fact, Chinese American social networks seem to be primarily kin-centered, even more so than 
Hispanic social networks that are well known to be kin-centered (Dong et al. 2012). Nuclear and extended family members, especially those in close neighborhood proximity, are the "most likely sources of unconditional support in health crises" (Dong and Chang 2017, 246). Again, these descriptive findings about the socioeconomic composition and influence of Chinese American enclaves suggest interactions and pathways to advance understanding about their possible protective effects. Supported by the theoretical framework of intersectionality which calls for an understanding of how multiple social identities may intersect to influence individual experience and that this intersection may "reflect multiple interlocking systems of privilege and oppression" (Bowleg 2012, 1267), this study explored the interaction of ethnicity, gender, and marital status on colon cancer outcomes among Chinese Americans residing in a specific culturally defined spatial context.

\section{Secondary analytic opportunity and hypotheses}

An archival database of colon cancer care and survival among those living in poverty during the 1990s and 2000s within California prior to the enactment of the Affordable Care Act (ACA) presented a secondary analytic opportunity (Gorey et al. 2011;2013; 2015). These historical cohort analyses originally found disadvantages among the poor that were largely accounted for by health insurance inadequacies across the care continuum--from waiting times for initial surgery, through receipt of adjuvant chemotherapy, to survival. This secondary analysis of the California database explored the following novel hypotheses related to Chinese American and Chinese American enclave advantages on survival:

1. There is an ethnicity by marital status interaction such that the protective effect of being married is greater among Chinese Americans (tested among the entire analytic sample). A sub-hypothesis was made that the protective effects of marriage was particularly true for 
Protective Effects of Ethnic Enclaves and Marriage

Chinese-American women, based on previous research which revealed that they were more likely to be married for longer periods of time.

2. There is an ethnic enclave by gender interaction such that the protective effect of living in a Chinese American enclave is greater for Chinese American women than for Chinese American men (tested among the Chinese American subsample).

\section{Methods \\ Original cohort}

A cancer registry-based colon cancer cohort of 6,300 people was established in California between 1995 and 2000, joined to the 2000 census by census tracts, and followed until enactment of the ACA in 2010. The California Cancer Registry is one of the most comprehensive and valid in North America with a 5-year loss to follow-up rate of less than $1 \%$. The original study oversampled the poor by randomly selecting a third of its participants from high poverty neighborhoods where $30 \%$ or more of the households were poor according to US Census Bureau criteria (Wilson 2012). The remainder were similarly selected from strata of $5 \%$ to $29 \%$ or less than $5 \%$ poor. This secondary analysis was restricted to 127 Chinese Americans and 4,524 other people with colon cancer. Chinese Americans were the most prevalent (25.1\%) Asian American group in the original sample. The remaining three-quarters of the Asian Americans were either born or had ancestry in 15 other Asian countries. They were excluded from this analysis for their lack of statistical power. The comparison group was comprised of 3,810 non-Hispanic white and 714 Hispanic people, chosen specifically for their previously demonstrated advantages in colon cancer care and survival. Primary health insurers were private, Medicare, Medicaid, or none. Based upon previous analyses of this cohort, inadequate insurance was defined as being uninsured or Medicaid-insured (Richter et al. 2015). No studies exist currently which define the 
minimum ethnic population density required for a neighborhood to be considered an Asian American or Chinese American enclave. We compared each 5\% ethnic concentration increment, from $5 \%$ to $75 \%$ Asian or Chinese American, with the average effect of the previous categories. Such reverse Helmert contrasts allowed for the identification of threshold effects that maximized predictive validity (Hosmer and Lemeshow 2000). The respective minimum thresholds of $30 \%$ Asian Americans and 10\% Chinese Americans were the most predictive. Thus, Asian American enclaves were defined as neighborhoods where $30 \%$ or more of the residents were Asian Americans. Chinese American enclaves were defined as neighborhoods where $10 \%$ or more of the residents were Chinese Americans.

\section{Secondary analysis of 5-year survival}

Age can confound any cancer analysis and stage of disease at diagnosis (i.e. I [localized] to IV [metastasized]) is intimately related to colon cancer survival. Cox regressions tested the two hypothesized interactions (Vittinghoff et al. 2012). Their significance was tested controlling for the confounding influences of age and disease stage. Neighborhood poverty did not significantly confound or substantially affect either regression model so it was removed from both. Both of the adjusted regression coefficients associated with the hypothesized interaction terms were statistically significant. Their modifying effects are described in the text and depicted in tables 2 and 3. For practical analyses, all 5-year survival rates were directly and internally age and stageadjusted and reported as percentages. Standardized rate ratios (RR) and rate differences (RD) were reported with $\chi^{2}$ test-based $95 \%$ confidence intervals (CI). Exploratory analyses of small subsamples reported $90 \%$ CIs. The original study was reviewed and cleared by the University of Windsor research ethics board and further methodological details were published (Gorey et al. $2011 ; 2013 ; 2015)$. 
Protective Effects of Ethnic Enclaves and Marriage

\section{Results \\ Description of samples}

Descriptive characteristics of the samples of Chinese Americans and other Americans (i.e. nonHispanic white or Hispanic) with colon cancer are displayed in Table 1. The original study's oversampling of people living in poverty seems to have produced remarkably similar ethnic samples. The Chinese and other Americans with colon cancer were similar on their gender and marital status distributions, as likely to live in relatively impoverished or affluent neighborhoods, and were diagnosed with similarly localized or advanced disease. Also, though they differed categorically on age, their respective mean ages of 68 and 70 did not differ significantly; $t(4,649)=1.60, p=.11$. Consistent with previous descriptions of Chinese Americans, there was a nonsignificant trend for more of them to be married and they were twice as likely to be inadequately insured, that is, uninsured or Medicaid insured (17.3\% vs. 8.3\%);

$\chi^{2}(1, N=4,651)=12.71, p<.05$.

\section{Interactions: Moderation of the protections associated with being Chinese American or living in a Chinese American enclave}

As hypothesized, a statistically significant ethnicity by marital status interaction was observed with a Cox regression which is depicted at the bottom of Table 2. First, respective null and modest main effects of ethnicity and marital status are displayed at the top of the table. Then, it becomes apparent that the protective effect of being married was much larger, approximately two-fold larger, for Chinese Americans $(\mathrm{RR}=1.31)$ than for the other study participants $(\mathrm{RR}=1.17)$. The married-unmarried 5-year survival rate difference was $14.2 \%$ among Chinese American, but only 7.7\% among the others. Regression support was not found for the sub- 
hypothesis of a gender by ethnicity by marital status interaction, likely because there was not enough statistical power to test this 3-way interaction confidently. However, the following descriptive exploration provided suggestive sub-hypothesis support. Adjusted 5-year survival among 13 unmarried Chinese American men was only 36.6\% versus 62.3\% among 35 married Chinese American women; RR $=1.70$ (90\% CI 1.04, 2.78). It seems that the protective effect of being married may be particularly advantaging for Chinese American women. This pattern was not observed among the sample of non-Hispanic white and Hispanic people.

A few more descriptive details may aid the interpretation of these observed or suggested interactions. First, being married was associated with private insurance coverage for all the study groups except Chinese American men and the association was especially strong among Chinese American women; married (54.3\% privately covered) versus unmarried $(22.9 \%), \mathrm{RR}=2.37$ (95\% CI 1.26, 4.45). Second, being married (97.5\%) versus unmarried (90.0\%) was associated with the receipt of surgery for Chinese Americans $(\mathrm{RR}=1.08,95 \%$ CI 1.00, 1.17), but not for others. Finally, being married (33.5\%) versus unmarried (26.4\%) was associated with the receipt of chemotherapy among all the study participants, Chinese American and non-Hispanic white/Hispanic people alike $(\mathrm{RR}=1.27,95 \% \mathrm{CI} 1.16,1.39)$.

As hypothesized, statistically significant ethnic enclave by gender interactions were observed among Chinese Americans with Cox regressions. Enclave protections were observed among Chinese American women only. For these women, the protective effect of living in an Asian American enclave was large $(\mathrm{RR}=1.37)$, but even larger in Chinese American enclaves $(\mathrm{RR}=1.59)$ as depicted in Table 3. In fact, the 5-year survival rate difference of $23.3 \%$, that characterized the difference between Chinese American women who lived in Chinese American enclaves (62.6\%) and those who did not (39.3\%), may be practically described as huge. It should 
be noted that there was substantial overlap between the Asian and Chinese American enclaves (point-biserial $r=.71, p<.05, r^{2}=.50[50.0 \%]$ ). About half, however, were non-overlapping. Again, descriptive details may aid the interpretation of these interactions. First, Chinese American women were more likely than Chinese American men to live in Chinese American enclaves; respectively, $61.4 \%$ and $45.6 \%, \mathrm{RR}=1.35(90 \%$ CI 1.02, 1.78). Second, Chinese American women who lived in Asian American enclaves were much less likely than Chinese American women who lived outside of such enclaves to experience long wait periods of 30 days or more for the initiation of their colon cancer treatment: $3.6 \%$ versus $13.3 \%, \mathrm{RR}=0.25(95 \% \mathrm{CI}$ 0.07, 0.96). Finally, the combined effect of being a married, Chinese American woman living in an Asian or Chinese American enclave was explored. The adjusted 5-year survival rate among the 16 married Chinese American women who lived in an Asian American enclave was 87.4\%. This was the highest survival rate of any group studied. The survival rate among the 24 unmarried Chinese Americans (survival rates of women and men did not differ) who did not reside in such an ethnic enclave was $29.2 \%$; $\mathrm{RR}=2.99(95 \% \mathrm{CI} 1.65,5.40)$. This was the largest survival rate ratio within this study's between-group comparisons.

\section{Discussion}

This longitudinal study explored the longer term protective health effects of living in ethnic enclaves among Chinese Americans. The Asian or Chinese American enclaves in California within this study were communities where most typically $50 \%$ of their residents were Asian Americans or $25 \%$ were Chinese Americans. The health outcome, 5-year colon cancer survival, is a sentinel indicator of health care access and effectiveness. Significant interactions were found at the individual and community levels: ethnicity by marital status and ethnic enclave by gender. Three-way interactions were also suggested: ethnicity by marital status by gender and ethnic 
enclave by gender by marital status. The findings demonstrated the relatively advantaged status of Chinese Americans as evidenced by their better survival, particularly those residing in Chinese American enclaves. Moreover, such protections were either exclusive to or appeared more pronounced, among Chinese American women, particularly those who were married. More exploratory evidence suggested that such married Chinese American women were more likely than unmarried Chinese American women to have private insurance coverage, less likely to experience extended wait periods for colon cancer care and more likely to receive indicated colon surgery and follow-up chemotherapy. Three further contextualizing points aid the interpretation of the practical and potential policy significance of these findings. First, the Chinese American participants were compared to other Americans, a comparison group composed of non-Hispanic white and Hispanic people who were already advantaged in colon cancer care and survival. Second, the Chinese Americans were more likely to be inadequately insured. Third, the 5-year survival rate among Chinese American women residing in Chinese American enclaves was $62.6 \%$ and the survival rate among the total comparison group was $49.6 \%$, a difference of $13 \%$. Colon cancer is a relatively common disease and Chinese Americans are a fast-growing population. Thus, while the difference in survival rates may be regarded as a small effect of modest significance, this rate difference would be greatly significant if it holds up to future, more rigorous, national study. Over the course of a generation, this population level would involve millions of people-Chinese Americans versus other Americans - with millions of years of life saved or lost.

Interdisciplinary researchers have long called for the study of interaction effects or at least, for more detailed descriptions of their participants that would enable such study (de Smidt and Gorey 1997; Lundahl, Yaffe and Hobson 2009; Videka-Sherman 1988). In addition to its 
Protective Effects of Ethnic Enclaves and Marriage

theoretical and policy implications, this study demonstrated the contemporary importance of understanding intersectionality and its influence on health outcomes (Bowleg 2012; Hulko 2009). If this had been a study of mere main effects, one might have concluded that ethnicity does not matter. Recall that prior to exploring interactions with gender, marital, and enclave statuses, no main effect of being Chinese American was observed. That is, their colon cancer survival rate was the same as that of the combined non-Hispanic white and Hispanic comparison group. The study of interactions, however, demonstrated that ethnicity matters profoundly. Chinese Americans, particularly married Chinese American women, seemed to experience multiple advantages by being Chinese American and living in neighborhoods where many other Chinese Americans lived.

The theory on Chinese American enclaves is just beginning to develop. Not surprisingly, being a married woman seems to potentiate their protective effects. There are well known advantages associated with marriage. Through marriage, women in America are much more likely to be privately insured by the best (e.g., gold or platinum) health plans through their or their spouses' employers (Wharam, Ross-Degnan and Rosenthal 2013). In addition to their greater access to work-related fringe benefits, married American women are generally known to have higher incomes, more wealth, and property than unmarried women (Grinstein-Weiss et al. 2011; Joyce 2007; Wilmoth and Koso 2002). Such advantages are likely to hold for married Chinese American women as well. The pattern of findings strongly suggests that the advantages of the general Asian American enclave and specific Chinese American enclave are greatest for married women. This also seems consistent with developing knowledge about their social networks. The networks in Chinese American enclaves seem to be almost exclusively (95\%) kin networks (Dong and Chang 2017). Secondary analysis was not conducted on these nuclear and 
extended family networks per se, but evidence suggesting the importance of marriage was uncovered. A spouse is probably central in most kin-based social networks. In addition to experiencing spousal support, married people naturally double their extended family network and likely its protective effects as well. The findings in this study indicate that Chinese American women were more likely to live in Chinese American enclaves than were Chinese American men. Beyond this, no research has been found which adequately explains their apparent large health advantages. Perhaps Chinese American women are better equipped to enlist and use the support of their kin. Indeed, the ability of co-ethnic members to converge in the social space of the ethnic enclave enables the building of social and economic capital (Zhou and Cho 2010) which may be used to absorb the direct (but uncovered) and indirect costs of health care. Future qualitative studies of Chinese Americans residing in Chinese American enclaves are needed to understand their lived experience of the enclave community and to advance theory about the advantages that such communities may provide.

Though not its central purpose, this study underscored the importance of health care policy which minimizes disparities in health insurance coverage. In this study, private insurance coverage was particularly prevalent among married Chinese American women. It also suggested that some of them, perhaps through larger, stronger, and more instrumental kin-based support networks, may be more able to cover the increasingly large, direct and indirect, out-of-pocket costs of cancer care in America. But what of those who cannot? The structural advantages associated with being married or living in certain neighborhoods among Chinese Americans were revealed. But what of the unmarried or those living in relatively disadvantaged neighborhoods? This study further exposed structural inequities related to the institutions of marriage, health care, and communities (Chinese American and others) that advantage some 


\section{Protective Effects of Ethnic Enclaves and Marriage}

while disadvantaging others. Policy makers ought to be cognizant of such social forces as reforms of the American health care system are considered.

\section{Potential limitations and further research needs}

First, these findings may not be generalizable to all Americans. However, given that one in ten Americans and one in three Chinese Americans live in California, they seem to have ample external validity (U.S. Census Bureau 2012; 2017). Admittedly, the original database overrepresented the poor and so, the findings are most representative of their experiences. Moreover, California expanded its Medicaid program more liberally under the ACA than most states (Hilman 2015). Thus, estimates of health care inequities are probably underestimates of the nation.

Second, this study's key analytic samples were modest (i.e., 127 Chinese Americans and 70 Chinese American women). Still, it had ample power to confidently detect its generally large effects (Fleiss, Levin and Paik 2003). The other samples (i.e., 4,524 non-Hispanic white or Hispanic people, of which 2,574 were married) essentially served as multiple "controls," bolstering statistical power. However, certain analyses of the increasingly specific experiences of Chinese American women or men, who were married or unmarried, and lived within an Asian or Chinese American enclave or not, were quite small with samples ranging from 13 to 43 . Some resultant findings were deemed significant with $90 \%$ confidence, rather than with the more scientifically conventional criterion of $95 \%$ confidence. Admittedly, these were exploratory, theory building analyses. Their outcomes are best regarded as developed hypotheses and researchers with access to national data are encouraged to test them.

A third way that this study was limited was its inability to account for acculturation. The original database was hospital and clinic-based, emphasizing cancer registration. Consequently, 
it did not routinely collect data on birthplace, immigration status, length of time since emigrating or social-familial processes related to acculturation. It was estimated that most of the Chinese American participants (87\%) were first-generation immigrants, but birthplace data was missing for more than half of them. It stands to reason that acculturation matters - the well-known diminishment of Hispanic paradoxical effects over successive immigrant generations being one example. It has also been suggested that certain tangible social supports may diminish with acculturation among Chinese Americans (Wong and Lu 2017). However, this suggestion was based on a modest cross-section study that did not account for enclave effects. Explorations of the effects of acculturation ought to be incorporated into the above-suggested, qualitative and quantitative studies.

\section{Conclusion}

This secondary analysis of a cohort of Chinese American people afflicted with colon cancer and living in poverty within California prior to the enactment of the ACA found consistent evidence of their relative protected status, particularly those residing in Chinese American enclaves. They consistently survived longer than similar non-Hispanic white or Hispanic people. Protective factors seemed most pronounced among Chinese American women, particularly those who were married. Exploratory evidence suggested that such married Chinese American women were more likely to have private insurance coverage, less likely to experience extended wait periods for treatment and more likely to receive indicated treatments. Mechanisms that explain these observed Chinese American advantages are not yet well understood, though their relatively large, kin-based social networks seem instrumental. Research on the influence of these social networks as well as the possible effects of acculturation are needed. There is much to learn from the strengths and resiliencies of such Chinese American communities. Finally, at every intersection 
Protective Effects of Ethnic Enclaves and Marriage

where a protection was identified, risks were also apparent. For example, what of the experiences of unmarried Chinese American men not living in Chinese American enclaves? These risks exposed structural inequities and disadvantages related to the institutions of marriage, health care and communities. Policy makers ought to be cognizant of such social forces as future reforms of the American health care system are considered. 


\section{Acknowledgements}

We acknowledge the administrative assistance of Kurt Snipes, Janet Bates and Gretchen Agha of the Cancer Surveillance and Research Branch, California Department of Public Health (CDPH) and Dee West and Marta Induni of the Cancer Registry of Greater California (CRGC). We also acknowledge the research or technical assistance of Glen Halvorson, Donald Fong and Arti Parikh-Patel of the CRGC and Madhan Balagurusamy, Daniel Edelstein and Nancy Richter of the University of Windsor. Finally, we acknowledge the assistance of Isaac Luginaah and Guangyong Zou of Western University, Eric Holowaty of the University of Toronto, Emma Bartfay of the University of Ontario Institute of Technology, Caroline Hamm and Sindu Kanjeekal of Windsor's Regional Cancer Center and Frances Wright of the Sunnybrook Health Sciences Center in obtaining funding or designing the database for this secondary analysis.

The collection of cancer incidence data used in this study was supported by the CDPH as part of the statewide cancer reporting program mandated by California Health and Safety Code; the National Cancer Institute's (NCI) Surveillance, Epidemiology and End Results Program under contracts awarded to the Cancer Prevention Institute of California, the University of Southern California, the Public Health Institute and the Centers for Disease Control and Prevention's (CDCP) National Program of Cancer Registries under an agreement awarded to the CDPH. The ideas and opinions expressed herein are those of the authors and endorsement by the State of California, the CDPH, the NCI or the CDCP or their contractors and subcontractors are not intended or should be inferred.

\section{Disclosure Statement}

No potential conflict of interest was reported by the authors.

\section{Funding}

Canadian Institutes of Health Research (grant 67161-2) and Ontario Graduate Scholarship. 
Protective Effects of Ethnic Enclaves and Marriage

\section{References}

Bowleg, L. 2012. "The Problem with the Phrase Women and Minorities: Intersectionalityan Important Theoretical Framework for Public Health.” American Journal of Public Health 102 (7): 1267-1273.

Campbell, D., Gorey, K.M., Luginaah, I.N., Zou G., Hamm, C. and Holowaty, E.J. 2016.

“Gender Differences on the Interacting Effects of Marital Status and Health Insurance on Long-Term Colon Cancer Survival in California, 1995-2014.” Public Health 140, 258-260.

Chang, Y. 2010. Writing the Ghetto: Class, Authorship, and the Asian American Ethnic Enclave. New Brunswick, N.J. : Rutgers University Press.

Chen, D.N., Song, C.G., Ouyang, Q.W., Jiang, Y.Z., Ye, F.G., Ma, F.J. et al. 2015. "Differences in Breast Cancer Characteristics and Outcomes between Caucasian and Chinese Women in the US.” Oncotarget 6, 14.

Chow, H.P.H. 2010. “Growing Old in Canada: Physical and Psychological Well-Being among Elderly Chinese Immigrants. Ethnicity \& Health 15 (1): 61-72.

de Smidt, G.A. and Gorey, K.M. 1997. “Unpublished Social Work Research: Systematic Replication of a Recent Meta-Analysis of Published Intervention Effectiveness Research.” Social Work Research 21 (1): 58-62.

Dong, X. and Chang, E.S. 2017. "Social Networks among the Older Chinese Population in the USA: Findings from the PINE Study.” Gerontology 63 (3): 238-252.

Dong, X., Chang, E.S., Wong, E. and Simon, M. 2012. “A Qualitative Study of Filial Piety among Community Dwelling, Chinese, Older Adults: Changing Meaning and Impact on Health and Well-Being.” Journal of Intergenerational Relationships 10 (2): 131-146. 
Protective Effects of Ethnic Enclaves and Marriage

Edwards, B.K., Noone, A.M., Mariotto, A.B., Simard, E.P., Boscoe, F.P., Henley, S.J. et al. 2014. "Annual Report to the Nation on the Status of Cancer, 1975-2010, Featuring Prevalence of Comorbidity and Impact on Survival among Persons with Lung, Colorectal, Breast, or Prostate Cancer.” Cancer 120 (9): 1290-1314.

Eschbach, K., Ostir, G.V., Patel, K.V., Markides, K.S. and Goodwin, J.S. 2004. "Neighborhood Context and Mortality among Older Mexican Americans: Is There a Barrio Advantage?" American Journal of Public Health 94 (10): 1807-1812.

Escobar, K.M., Sivaram, M. and Gorey, K.M. 2018. "Multiplicative Advantages of Hispanic Men Living in Hispanic Enclaves: Intersectionality in Colon Cancer Care.” Manuscript submitted for publication.

Fleiss, J.L., Levin, B. and Paik, M.C. 2003. Statistical Methods for Rates and Proportions (3rd ed.). New York, NY: John Wiley \& Sons.

Gomez, S.L., Clarke, C.A., Shema, S.J., Chang, E.T., Keegan, T.H.M. and Glaser, S.L. 2010. "Disparities in Breast Cancer Survival among Asian Women by Ethnicity and Immigrant Status: A population-Based Study.” American Journal of Public Health 100 (5): 861-869. Gorey, K.M., Kanjeekal, S.M., Wright, F.C., Hamm, C., Luginaah, I.N., Bartfay, E. et al. 2015. "Colon Cancer Care and Survival: Income and Insurance are More Predictive in the USA, Community Primary Care Physician Supply More so in Canada.” International Journal for Equity in Health 14, 109.

Gorey, K.M., Luginaah, I.N., Bartfay, E., Zou, G., Haji-Jama, S., Holowaty, E.J. et al. 2013. "Better Colon Cancer Care for Extremely Poor Canadian Women Compared with American Women.” Health \& Social Work 38 (4): 240-248. 


\section{Protective Effects of Ethnic Enclaves and Marriage}

Gorey, K.M., Luginaah, I.N., Bartfay, E., Fung, K.Y., Holowaty, E.J., Wright, F.C. et al. 2011. “Effects of Socioeconomic Status on Colon Cancer Treatment Accessibility and Survival in Toronto, Ontario, and San Francisco, California, 1996-2006. American Journal of Public Health 101 (1): 112-119.

Grinstein-Weiss, M., Charles, P., Guo, S., Manturuk, K. and Key, C. 2011. "The Effect of Marital Status on Home Ownership among Low-Income Households.” Social Service Review 85 (3): 475-503.

Hashiguchi, Y., Hase, K., Ueno, H., Shinto, E., Naito, Y., Kajiwara, Y. et al. 2012. "Impact of Race/Ethnicity on Prognosis in Patients who Underwent Surgery for Colon Cancer: Analysis for White, African, and East Asian Americans.” Annals of Surgical Oncology 19 (5): 1517-1528.

Hilman, J. 2015. 5 Years into the Affordable Care Act: California Leads the Way. Sacramento, CA: Health Access California.

Hosmer, D.W. and Lemeshow, S. 2000. Applied logistic regression, 2nd ed. New York, NY: John Wiley \& Sons.

Hulko, W. 2009. “The Time- and Context-Contingent Nature of Intersectionality and Interlocking Oppressions.” Affilia: Journal of Women and Social Work 24 (1): 44-55.

Joyce, J.A. 2007. Women, Marriage and Wealth: The Impact of Marital Status on the Economic Well-Being of Women through the Life Course. New York, NY: Gordian Knot Books.

Levitz, N R., Haji-Jama, S., Munro, T., Gorey, K.M., Luginaah, I.N., Bartfay, E. et al. 2015. "Multiplicative Disadvantage of being an Unmarried and Inadequately Insured Woman Living in Poverty with Colon Cancer: Historical Cohort Exploration in California. BMC Women's Health 15, 8. 
Lin, S.S., Clarke, C.A., Prehn, A.W., Glaser, S.L., West, D.W. and O’Malley, C.D. 2002.

"Survival Differences among Asian Subpopulations in the United States after Prostate, Colorectal, Breast, and Cervical Carcinomas.” Cancer 94 (4): 1175-1182.

Lin, J., Qiu, M., Xu, R. and Dobs, A.S. 2015. "Comparison of Survival and Clinicopathologic Features in Colorectal Cancer among African American, Caucasian, and Chinese patients Treated in the United States: Results from the Surveillance Epidemiology and End Results (SEER) Database." Oncotarget 6, 32.

Lundahl, B., Yaffe, J. and Hobson, J. 2009. “Today’s Studies, Tomorrow's Meta-Analyses: Implications for Evidence Informed Decision-Making in Social Work. Journal of Social Service Research 35 (1): 1-9.

Luo, R.L., Freeman, J., Freeman, D. and Weaver, J., March, 2004. A Population Based Study in Colon Cancer Survival among Non-Hispanic Whites and Asian-American Subgroups [abstract]. Presented at the $9^{\text {th }}$ Biennial Symposium on Minorities, the Medically Underserved \& Cancer Program. Washington, DC.

Markides, K. and Coreil, J. 1986. "The Health of Hispanics in the Southwestern United States: An Epidemiological Paradox.” Public Health Reports 101 (3): 253-265.

McWilliams, J.M., Zaslavsky, A.M., Meara, E. and Ayanian, J.Z. 2004. "Health Insurance Coverage and Mortality among the Near-Elderly.” Health Affairs 23 (4): 223-233. Osypuk, T.L., Diez Roux, A.V., Hadley, C. and Kandula, N. 2009. “Are Immigrant Enclaves Healthy Places to Live? The Multi-Ethnic Study of Atherosclerosis.” Social Science \& Medicine 69 (1): 110-120.

Pew Research Center 2017. Social and Demographic Trends: The Rise of Asian Americans. Accessed June 7. http://www.pewsocialtrends.org/asianamericans-graphics/. 
Protective Effects of Ethnic Enclaves and Marriage

Public Policy Institute of California 2017. Immigrants in California. Accessed June 7. http://www.ppic.org/main/publication_show.asp?i=258.

Richter, N.L., Gorey, K.M., Haji-Jama, S. and Luginaah, I.N. 2015. "Care and Survival of Mexican American Women with Node Negative Breast Cancer: Historical Cohort Evidence of Health Insurance and Barrio Advantages.” Journal of Immigrant and Minority Health 17 (3): 652-659.

Ruiz, J.M., Steffen, P. and Smith, T.B. 2013. "Hispanic Mortality Paradox: A Systematic Review and Metaanalysis of the Longitudinal Literature.” American Journal of Public Health 103 (3): e52-60.

Simon, M.A., Li, Y. and Dong, X. 2014. "Levels of Health Literacy in a Community-Dwelling Population of Chinese Older Adults.” Journals of Gerontology: Medical Sciences 69A (S2): S54-S60.

Sun, L.M., Li, C.I., Huang, E.Y. and Vaughan, T.L. 2007. "Survival Differences by Race in Nasopharyngeal Carcinoma. American Journal of Epidemiology 165 (3): 271-278.

Tan, J. 2009. Health Service Utilization among Chinese, Filipino, and Asian Indian Older Adults in the United States (doctoral dissertation). Washington University, St. Louis, MO.

Todd, L., Harvey, E. and Hoffman-Goetz, L. 2011. "Predicting Breast and Colon Cancer Screening among English-as-a-Second-Language Older Chinese Immigrant Women to Canada.” Journal of Cancer Education 26 (1): 161-169.

Turra, C M. and Goldman, N. 2007. "Socioeconomic Differences in Mortality among US Adults: Insights into the Hispanic Paradox.” Journals of Gerontology: Psychological Sciences and Social Sciences 62B (3): S184-S192. 
U.S. Census Bureau 2017. Race Reporting for the Asian Population by Selected Categories: 2010 Census Summary File 1. Accessed June 7. https://factfinder.census.gov/faces/ tableservices/jsf/pages/productview.xhtml?pid=DEC 10 SF1 QTP8\&prodType=table.

U.S. Census Bureau 2012. 2010 Census of Population and Housing: Summary Tape File 3 by States on CD-ROM. Washington, DC: U. S. Department of Commerce.

Videka-Sherman, L. 1988. "Metaanalysis of Research on Social Work Practice in Mental Health.” Social Work 33 (4): 325-338.

Vittinghoff, E., Glidden, D V., Shiboski, S.C. and McCulloch, C.E. 2012. Regression Methods in Biostatistics: Linear, Logistic, Survival, and Repeated Measures Models (2nd ed.). New York, NY: Springer.

Walton, E. 2015. "Making Sense of Asian American Ethnic Neighborhoods: A Typology and Application to Health.” Sociological Perspectives 58 (3): 490-515.

Wen, K.Y., Fang, C.Y. and Ma, G.X. 2014. "Breast Cancer Experience and Survivorship among Asian Americans: A Systematic Review.”Journal of Cancer Survivorship 8 (1): 94-107.

Wharam, J.F., Ross-Degnan, D. and Rosenthal, M.B. 2013. "The ACA and High-Deductible Insurance —-Strategies for Sharpening a Blunt Instrument.” New England Journal of Medicine 369 (16): 1481-1484.

Wilmoth, J. and Koso, G. 2002. "Does Marital History Matter? Marital Status and Wealth Outcomes among Preretirement Adults.” Journal of Marriage and Family 64 (1): 254-268. Wilson, W.J. 2012. The Truly Disadvantaged: The Inner City, the Underclass, and Public Policy (2nd ed.). University of Chicago Press. 
Protective Effects of Ethnic Enclaves and Marriage

Wong, C.C.Y. and Lu, Q. 2017. "Match between Culture and Social Support: Acculturation Moderates the Relationship between Social Support and Well-Being of Chinese American Breast Cancer Survivors.” Quality of Life Research 26 (1): 73-84.

Xu, C., Chen, Y.P., Liu, X., Tang, L.L., Chen, L., Mao, Y. et al. 2017. "Socioeconomic factors and Survival in Patients with Non-Metastatic Head and Neck Squamous Cell Carcinoma." Cancer Science 108 (6): 1253-1262.

Zhou, M. \& Cho, M. 2010. "Noneconomic Effects of Ethnic Entrepreneurship: A Focused Look at the Chinese and Korean Enclave Economies in Los Angeles.” Thunderbird International Business Review 52 (2): 83-96.

Zhou, M. \& Logan, J.R. 1989. “Returns on Human Capital in Ethnic Enclaves: New York City’s Chinatown.” American Sociological Association 54 (5): 809-820. 
Protective Effects of Ethnic Enclaves and Marriage

Table 1. Descriptions of 127 Chinese Americans and 4,524 other Americans ${ }^{\mathrm{a}}$ with colon cancer

$$
\text { Chinese Americans, }{ }^{b} \text { No. (\%) Other Americans, No. (\%) }
$$

$$
\begin{aligned}
& \text { Age at diagnosis } \\
& 25-59 \\
& 60-69 \\
& 70-79 \\
& \geq 80
\end{aligned}
$$

Women

Marital status

Married

Never married

Separated or divorced

Widowed

Neighborhood poverty prevalence $(\%)$

$$
\begin{aligned}
& <5 \\
& 5-19 \\
& \geq 20
\end{aligned}
$$

\section{Primary health insurer*}

Private

Medicare

Medicaid

None $^{\mathrm{c}}$

Stage at diagnosis ${ }^{\mathrm{d}}$

I
II
III
IV

37
25
29
36

70

55.1

79

62.2

$\begin{array}{ll}11 & 8.7\end{array}$

$5 \quad 3.9$

$32 \quad 25.2$

$49 \quad 38.6$

36.2

46

32

25.2

1,509

1,498

33.4

1,517

33.1

2,574

56.9

436

9.7

1,073

23.7

$\begin{array}{rr}52 & 40.9 \\ 53 & 41.7 \\ 12 & 9.4 \\ 10 & 7.9\end{array}$

2,087

46.1

2,060

158

45.5

219

3.5

4.8

984

21.8

26

20.5

1,492

1,094

33.0

29.1

954

$22 \quad 17.3$

21.1

a 3,810 non-Hispanic white and 714 Hispanic people.

${ }^{\mathrm{b}}$ Most (87\%) were first generation immigrants born in China. However, birthplace was missing for more than half of the participants (54\%) and nonspecific for most of them (80\% [unknown whether they were born in the Peoples Republic of China, Taiwan or Hong Kong]).

${ }^{\mathrm{c}}$ Low representation of the uninsured may seem surprising. Note that colon cancer care takes place in hospitals where social workers work to connect uninsured people to Medicaid or Medicare.

${ }^{\mathrm{d}}$ Another biomarker, tumor differentiation or grade, did not differ significantly between ethnic groups.

${ }^{*}$ Ethnic group differences were statistically significant $\left(\chi^{2}\right.$ test, $\left.p<.05\right)$. 
Protective Effects of Ethnic Enclaves and Marriage

Table 2. Main effects and interaction of ethnicity and marital status on 5-year colon cancer survival $(N=4,651)$

$$
\text { No. }{ }^{a} \text { Rate }(\%)^{\mathrm{b}} \quad \mathrm{RR}^{\mathrm{c}} \quad 95 \% \mathrm{CI} \quad \mathrm{RD}
$$

Ethnicity by marital status interaction

\section{Others}

Main effects of ethnicity and marital status

Ethnicity

Others

Chinese Americans

$4,524 \quad 49.6 \quad 1.00$

$127 \quad 55.5 \quad 1.12$

$0.93,1.34$

$5.9 \%$

Marital status

Not married

1,998

45.3

1.00

Married

2,653

53.1

1.17

$1.10,1.24$

$7.8 \%$

Not married

Married

Chinese Americans

Not married

Married

$$
1,950
$$

2,574

45.2

52.9

1.00

$\mathbf{1 . 1 7}$

$1.10,1.24$

$7.7 \%$

Notes. $\mathrm{CI}=$ confidence interval, $\mathrm{RR}=$ standardized rate ratio, $\mathrm{RD}=$ standardized rate difference. Bolded RRs or RDs were minimally statistically significant $\left(\chi^{2}\right.$-based CI, $\left.p<.10\right)$.

${ }^{a}$ Number of people with colon cancer.

${ }^{\mathrm{b}}$ Age and stage-adjusted 5-year survival.

${ }^{\mathrm{c}}$ A rate ratio of 1.00 was the within-group baseline.

d $90 \%$ CI. 
Table 3. Main effects of ethnic enclaves on 5-year colon cancer survival among Chinese American women $(N=70)$

$$
\text { No. }^{\mathrm{a}} \text { Rate }(\%)^{\mathrm{b}} \quad \mathrm{RR}^{\mathrm{c}} \quad 95 \% \mathrm{CI} \quad \mathrm{RD}
$$

Neighborhood Asian American prevalence

$$
\begin{array}{ll}
<30 \%(0.9 \% \text { to } 29.3 \%, M d n=11.9 \%) & 34 \\
\geq 30 \%(30.3 \% \text { to } 95.1 \%, M d n=51.0 \%)^{\text {d }} & 36
\end{array}
$$

1.00

1.37

$1.00,1.87^{\mathrm{e}}$

$17.7 \%$

Neighborhood Chinese American prevalence

$$
\begin{aligned}
& <10 \%(0.1 \% \text { to } 8.3 \%, M d n=2.7 \%) \quad 27 \\
& \geq 10 \%(10.0 \% \text { to } 92.1 \%, M d n=26.7 \%)^{\mathrm{f}} 43 \\
& 62.6
\end{aligned}
$$$$
39.3
$$

1.57

...

$1.04,2.37$

$22.7 \%$

Notes. $\mathrm{CI}=$ confidence interval, $\mathrm{RR}=$ standardized rate ratio, $\mathrm{RD}=$ standardized rate difference. Bolded $\mathrm{RRs}$ or RDs were minimally statistically significant $\left(\chi^{2}\right.$-based CI, $\left.p=.05\right)$. One strata of the ethnic enclave by gender interactions, that is, the female strata, is depicted. The male strata are not depicted as the main effects of ethnic

${ }^{\mathrm{e}} \mathrm{p}=.05$. 
Protective Effects of Ethnic Enclaves and Marriage

Table 1. Descriptions of 127 Chinese Americans and 4,524 other Americans ${ }^{\mathrm{a}}$ with colon cancer

$$
\text { Chinese Americans, }{ }^{\mathrm{b}} \text { No. (\%) Other Americans, No. (\%) }
$$

$$
\begin{aligned}
& \text { Age at diagnosis } \\
& 25-59 \\
& 60-69 \\
& 70-79 \\
& \geq 80
\end{aligned}
$$

Women

Marital status

Married

Never married

Separated or divorced

Widowed

Neighborhood poverty prevalence $(\%)$

$$
\begin{aligned}
& <5 \\
& 5-19 \\
& \geq 20
\end{aligned}
$$

Primary health insurer
Private
Medicare
Medicaid
None $^{\text {c }}$

Stage at diagnosis ${ }^{\mathrm{d}}$$$
\text { I }
$$

II

III

IV

37

25

29

36

70

55.1

79

11

5

32

49

46

38.6

36.2

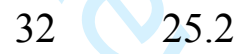

52

53

12

10

40.9

41.7

9.4

7.9

\section{6}

42

37

22
20.5

33.1

29.1

17.3

$\begin{array}{rr}924 & 20.4 \\ 991 & 21.9 \\ 1,449 & 32.0 \\ 1,160 & 25.6\end{array}$

2,312

51.1

2,574

56.9

$441 \quad 9.7$
436

$436 \quad 9.6$

$1,073 \quad 23.7$

1,509

33.4

1,498

33.1

$1,517 \quad 33.5$

2,087

46.1

2,060

45.5

158

3.5

$219 \quad 4.8$

a 3,810 non-Hispanic white and 714 Hispanic people.

${ }^{\mathrm{b}}$ Most (87\%) were first generation immigrants born in China. However, birthplace was missing for more than half of the participants (54\%) and nonspecific for most of them (80\% [unknown whether they were born in the Peoples Republic of China, Taiwan or Hong Kong]).

${ }^{\mathrm{c}}$ Low representation of the uninsured may seem surprising. Note that colon cancer care takes place in hospitals where social workers work to connect uninsured people to Medicaid or Medicare.

${ }^{\mathrm{d}}$ Another biomarker, tumor differentiation or grade, did not differ significantly between ethnic groups.

${ }^{*}$ Ethnic group differences were statistically significant $\left(\chi^{2}\right.$ test, $\left.p<.05\right)$. 
Protective Effects of Ethnic Enclaves and Marriage

Table 2. Main effects and interaction of ethnicity and marital status on 5-year colon cancer survival $(N=4,651)$

$$
\text { No. }^{\mathrm{a}} \text { Rate }(\%)^{\mathrm{b}} \quad \mathrm{RR}^{\mathrm{c}} \quad 95 \% \mathrm{CI} \quad \mathrm{RD}
$$

Ethnicity by marital status interaction

\section{Others}

Main effects of ethnicity and marital status

Ethnicity

Others

Chinese Americans

Marital status

Not married

Married

$\begin{array}{lll}4,524 & 49.6 \quad 1.00\end{array}$

$127 \quad 55.5 \quad 1.12$

$0.93,1.34$

$5.9 \%$

1,998

45.3

1.00

$53.1 \quad 1.17$

$1.10,1.24$

$7.8 \%$
Not married

Married

Chinese Americans

Not married

Married

\section{1,950}

2,574

45.2

52.9

1.00

1.17

$1.10,1.24$

$7.7 \%$

Notes. $\mathrm{CI}=$ confidence interval, $\mathrm{RR}=$ standardized rate ratio, $\mathrm{RD}=$ standardized rate difference. Bolded $\mathrm{RRs}$ or RDs were minimally statistically significant $\left(\chi^{2}\right.$-based $\left.\mathrm{CI}, p<.10\right)$.

${ }^{a}$ Number of people with colon cancer.

${ }^{\mathrm{b}}$ Age and stage-adjusted 5-year survival.

${ }^{\mathrm{c}}$ A rate ratio of 1.00 was the within-group baseline.

d $90 \%$ CI. 
Table 3. Main effects of ethnic enclaves on 5-year colon cancer survival among Chinese American women $(N=70)$

$$
\text { No. }^{\mathrm{a}} \text { Rate }(\%)^{\mathrm{b}} \quad \mathrm{RR}^{\mathrm{c}} \quad 95 \% \mathrm{CI} \quad \mathrm{RD}
$$

Neighborhood Asian American prevalence

$$
\begin{array}{ll}
<30 \%(0.9 \% \text { to } 29.3 \%, M d n=11.9 \%) & 34 \\
\geq 30 \%(30.3 \% \text { to } 95.1 \%, M d n=51.0 \%)^{d} & 36
\end{array}
$$

1.00

1.37

$1.00,1.87^{\mathrm{e}}$

$17.7 \%$

Neighborhood Chinese American prevalence

$$
\begin{aligned}
& <10 \%(0.1 \% \text { to } 8.3 \%, M d n=2.7 \%) \quad 27 \\
& \geq 10 \%(10.0 \% \text { to } 92.1 \%, M d n=26.7 \%)^{\mathrm{f}} 43 \\
& 62.6
\end{aligned}
$$$$
39.3
$$

1.57

...

$1.04,2.37$

$22.7 \%$

Notes. $\mathrm{CI}=$ confidence interval, $\mathrm{RR}=$ standardized rate ratio, $\mathrm{RD}=$ standardized rate difference. Bolded $\mathrm{RRs}$ or RDs were minimally statistically significant $\left(\chi^{2}\right.$-based CI, $\left.p=.05\right)$. One strata of the ethnic enclave by gender interactions, that is, the female strata, is depicted. The male strata are not depicted as the main effects of ethnic

${ }^{\mathrm{e}} \mathrm{p}=.05$. 